\title{
HOMOGRAPHIC PROPER NAMES: ON PECULIARITIES OF PRONUNCIATION REGISTRATION
}

\author{
Natalya K. Ivanova \\ Ivanovo State University of Chemistry and Technology, Ivanovo, Russia \\ Rimma V. Kuzmina \\ Ivanovo State University of Chemistry and Technology, Ivanovo, Russia
}

\begin{abstract}
The article considers phonetic variants of English proper names that comprise homographic groups, and some impairments during their registration in pronouncing dictionaries. The authors present the results of lexicographic and comparative analysis of units extracted from two pronouncing dictionaries: "Cambridge English Pronouncing Dictionary" by D. Jones and "Longman Pronunciation Dictionary" by J. Wells using the continuous sampling method. Particular attention is focused on the methods of registration and completeness of phonetic notation of homographs pronunciation. A number of peculiarities are noted in recording semantics, phonetic-and-orthographic variations in some homogroups in British and American English. Clear inconsistency and insufficiency of lexicographic parametrization of both homographic proper names and their national and social pronunciation variants, as well as the meanings of common and proper names are revealed. The conclusion is made about the accuracy of "Cambridge English Pronouncing Dictionary" in terms of registering several British and American variants of onyms pronunciation, supplemented by additional comments on the phonetic variants and meanings of numerous types of proper names (anthroponyms, toponyms, ergonyms). The data obtained are required for differentiating the meanings of proper names, correct use of onyms and appellatives in oral speech, as well as for compiling dictionaries and reference books.

Key words: English language, proper name, homonymy, homograph, phonetic variant, pronouncing dictionary.

Citation. Ivanova N.K., Kuzmina R.V. Homographic Proper Names: On Peculiarities of Pronunciation Registration. Vestnik Volgogradskogo gosudarstvennogo universiteta. Seriya 2. Yazykoznanie [Science Journal of Volgograd State University. Linguistics], 2020, vol. 19, no. 2, pp. 98-111. (in Russian). DOI: https://doi.org/ 10.15688/jvolsu2.2020.2.9
\end{abstract}

\section{ОСОБЕННОСТИ РЕГИСТРАЦИИ ПРОИЗНОШЕНИЯ АНГЛИЙСКИХ ОМОГРАФИЧНЫХ ИМЕН СОБСТВЕННЫХ}

\author{
Наталья Кирилловна Иванова \\ Ивановский государственный химико-технологический университет, г. Иваново, Россия \\ Римма Владимировна Кузьмина \\ Ивановский государственный химико-технологический университет, г. Иваново, Россия
}

Аннотация. В статье рассматриваются фонетические варианты английских имен собственных, входящих в группы омографов, и особенности их регистрации в орфоэпических словарях. Представлены результаты лексикографического и сравнительно-сопоставительного анализа единиц, извлеченных методом сплошной выборки из двух орфоэпических словарей: «Cambridge English Pronouncing Dictionary» Д. Джоунза и «Longman Pronunciation Dictionary» Дж. Уэллса. Особое внимание уделено способам регистрации и полноте представления произношения омографов. Установлены особенности в описании семантики и фонетико- 
орфографической вариантности в некоторых омогруппах в британском и американском вариантах английского языка. Выявлена непоследовательность и недостаточность лексикографической параметризации как омографичных имен собственных и их национальных и социальных вариантов произношения, так и значений нарицательных и собственных имен. Сделан вывод о преимуществах «Cambridge English Pronouncing Dictionary» в регистрации нескольких британских и американских вариантов произношения онимов, в наличии дополнительных комментариев о произносительных вариантах и значений различных видов имен собственных (антропонимов, топонимов, эргонимов). Полученные в результате исследования данные позволят дифференцировать значения имен собственных, могут способствовать корректному употреблению онимов и апеллятивов в устной речи и будут полезны при составлении словарей и справочников.

Ключевые слова: английский язык, имя собственное, омонимия, омограф, вариант произношения, орфоэпический словарь.

Цитирование. Иванова Н. К., Кузьмина Р. В. Особенности регистрации произношения английских омографичных имен собственных // Вестник Волгоградского государственного университета. Серия 2, Языкознание. 2020. - T. 19, № 2. - C. 98-111. - DOI: https://doi.org/10.15688/jvolsu2.2020.2.9

\section{Введение}

Все имена собственные, окружающие определенный человеческий коллектив, находятся, как известно, в слаженном взаимодействии. А.В. Суперанская в книге «Что такое топонимика?» отмечает: «Ономастический континуум характеризуется теснейшей связью собственных имен разных типов друг с другом. Он развивается, как и все явления нашей действительности, в пространстве и во времени. Но есть у него и своя специфика. Помимо этих параметров, присущих всем явлениям действительности, он характеризуется еще и культурной непрерывностью, то есть особой связью имен, созданных людьми разных стран и культур. Поэтому выделение топонимов в отдельный ономастический класс в известной мере условно» [Суперанская, 1985, с. 9].

Исходя из этой концепции, мы рассматриваем такие разновидности английских имен собственных (далее - ИС), как антропонимы, топонимы, эргонимы, идеонимы, выделяем эти классы тоже условно, обращая внимание на их омонимичность и особенности произношения и написания. Поскольку одна графическая форма слова может передавать на письме одновременно и антропоним, и топоним, например Bury 'place': /'ber.i/ и 'surname': /'bjuə.ri/, фонетическая форма позволяет их дифференцировать. Таким образом, имя собственное Bury, оказавшись сразу в двух ономастических классах, совпадает по написанию с глаголом bury v/'ber.i/ 'хоронить, зарывать в землю', а как топоним совпадает с этим глаголом и по произношению. Этот пример демонстрирует существование феномена омонимии среди онимов и апеллятивов, факт наличия которой давно известен и описан в языкознании на материале различных языков, однако, на наш взгляд, до сих пор не получил должного отражения в словарях, в том числе орфоэпических. Так, на материале русского языка в книге А.В. Суперанской и А.В. Сусловой «Современные русские фамилии» была предложена классификация, которая указывает на наличие определенной универсальности во взаимоотношениях между именами собственными и нарицательными, характерной для ряда языков. Приведем цитату из книги указанных авторов, но с усеченным количеством примеров: «Выделяются многочисленные ряды омонимов, где одно из созвучных слов имя нарицательное, а другое - собственное. Например, Майор 1) воинское звание, 2) личное имя; Златоуст 1) кто красиво говорит, 2) второе имя Иоанна Златоуста; Надежда 1) абстрактное существительное, 2) имя; Лев 1) животное, 2) знак зодиака, 3) имя; Буй 1) буйный человек, 2) поплавок на якоре, 3 ) город Костромской области; Гаврик 1) орловское 'простак', 2) тульское 'щеголь', 3) пензенское 'хитрец', 4) сокращение от имени Гаврила (Гавриил)» [Суперанская, Суслова, 1981, с. 56-57].

Англоязычные имена собственные в работах отечественных и зарубежных ученых подробно рассматриваются в этимологическом, семантическом и функциональном аспектах [Леонович, Сизова, 2018], иссле- 
дуются с применением морфосинтаксического подхода [The Oxford Handbook..., 2016, p. 20], при этом отмечается тонкая грань перехода онимов в созвучные им апеллятивы и наоборот. Таким образом, поднимается вопрос омонимии и подчеркивается, что «языковая единица определяется как собственное или нарицательное имя только при ее употреблении» [Горяев, Спиридонов, 2016, с. 192].

Исследованию ономастических проблем на материале различных языков посвящен ряд авторитетных работ [Алпатов, 2013; Березович, 2001; Ильин, 2017; 2018; Леонович, 1990; Суперанская, Суслова, 1981; Callary, 2012; Owen, 1981; Parsons, 2013; Perono Cacciafoco, 2013; Postles, 2002; и др.].

Однако публикаций, нацеленных на выявление собственно фонетической вариантности имен собственных, омонимичных с апеллятивами, обнаружено не было, а ведь именно она зачастую определяет особенности семантики и написания многочисленных омонимов.

\section{Материал и методы исследования}

Предметом нашего исследования являются особенности регистрации омографичных имен собственных в орфоэпических словарях «Longman Pronunciation Dictionary» Дж. Уэллса (LPD) и «Cambridge English Pronouncing Dictionary» Д. Джоунза (EPD) как важнейших источниках достоверной лингвистической информации об омографах, возникших в процессе исторического развития английского языка. Мы также проводим анализ фонетических вариантов английских имен собственных, входящих в группы омографов, полноты и наглядности их представления в словниках сопоставляемых словарей.

В результате сплошной выборки входных единиц из 1-го и 2-го изданий LPD нами составлен основной корпус исследования 740 графических омогрупп (это число мы взяли за $100 \%$ ). Из них чуть более четверти (195 омогрупп - 26,35\%) включают в себя имена собственные. Словарные статьи (с выявленными в LPD омогруппами с онимами) сопоставлялись со словарными материалами 18-го издания EPD.
Данные словари являются в настоящее время самыми авторитетными орфоэпическими справочниками в англоязычной лексикографии, в которых приводятся и британские, и американские варианты произношения, нередко различающиеся между собой, однако отражающие национальные особенности произношения английских слов. В указанных словарях с помощью специально разработанной системы помет (в LPD) и/или посредством комментариев (в LPD и EPD) также регистрируются социальные и контекстуальные произносительные варианты лексических единиц, особенности их семантики.

В данной статье проведен лексикографический анализ вариантности произношения английских имен собственных, составляющих графические омогруппы с апеллятивами, а также сравнительно-сопоставительный анализ способов представления произношения ИС, входящих в омогруппы, в LPD и EPD с целью установить сходства и различия в регистрации произношения и выявить полноту данных, необходимых для дифференциации значения ИС и, как следствие, корректного употребления их в устной речи, установленного по словарям.

Получение таких данных необходимо как в лингвистическом плане, так и в прагматическом - для повышения культуры речи носителей английского языка и всех, кто изучает его как иностранный язык. Для нашей страны это особенно актуально, поскольку во многих учебных пособиях и справочниках информация о произношении имен собственных (выдающихся ученых, императоров, святых, а также национальных топонимов и т. д.) или не приводится, или представлена неполно, некорректно.

Под графической омогруппой мы понимаем лексическую группу из двух и более графических омонимов (омографов) - слов, идентичных по написанию, но различных по произношению и значению. Ранее нами рассматривались графические омогруппы, состоящие исключительно из имен собственных (было выявлено 74 группы таких омографов, это $10 \%$ от общего количества омографичных групп), и были выявлены фонетические средства различения антропонимов, топонимов и частично эргонимов в рамках омони- 
Н.К. Иванова, Р.В. Кузьмина. Особенности регистрации произношения английских омографичных ИС

мии [Иванова, Кузьмина, Мощева, 2014; Кузьмина, 2009; 2017].

В данной статье продемонстрированы особенности регистрации в орфоэпических словарях произносительных характеристик групп омографов, в которых одно слово - антропоним, топоним или эргоним, а другое слово (иногда 2, 3 или 4 слова) не является именем собственным (обнаружена 121 такая группа, это 16,35\%). Полный список омографов, составленный по результатам сплошной выборки из LPD, опубликован в одной из наших работ [Кузьмина, 2007, c. 216-258]. Среди 121 группы омографов обнаружено 2 омогруппы из 4 слов и 3 омогруппы из 5 слов, остальные 116 групп представляют собой двойки или тройки идентичных по написанию слов.

\section{Результаты и обсуждение}

\section{I. Полное совпадение регистрации} в LPD и EPD всех произносительных вариантов ИС, входящих в омографичные группы, было обнаружено, например, в следующих парах / тройках слов: ally $v$-ally $n-$ Ally 'personal name'; askew - Askew; bug Bug; Capote - capote; chevy, C - Chevy; espy - Espy; fan - Fan; hades - Hades; hag - HAG; job - Job; Leister - leister; Les les; levy - Levy; nan - Nan; natal - Natal; main - Main; Neve - névé; nice - Nice; Outspan - outspan; Po - Po; prestige Prestige; reading - Reading; rose, Rose rosé; scone - Scone; slough - Slough; trierTrier; wan - WAN.

Проиллюстрируем это на словарных примерах (табл. 1). Следует отметить, что в таблицах (здесь и далее) все словарные единицы, указание на их частеречную принадлежность, семантические комментарии, фоноварианты и другая информация приводятся в соответствии с оригинальными источниками.

Как можно заметить из этих словарных статей, все варианты произношения и имен собственных, и имен нарицательных совпадают в обоих словарях, но в EPD отсутствует указание на семантику ИС, которая, как видно из приведенных примеров, дифференцирует оним и апеллятив посредством различного произношения.

II. Достоинства словаря EPD в регистрации фонетической вариантности на примере ИС:

1. B EPD, в отличие от LPD, в одной словарной статье приводится более обширная информация о вариантах произношения ИС с указанием на их употребление в зависимости от семантики. Такие примеры, однако, немногочисленны, и к ним можно отнести Dives, Gill. Покажем это в сравнении (см. табл. 2; различия подчеркнуты нами).

Итак, в одной словарной статье на ИС Dives в EPD приводятся (с семантическим комментарием) два фонетических варианта произношение библейского имени и произношение обычной фамилии. В словарной статье на ИC Gill в EPD дается более подробный, чем в LPD, комментарий о фоновариантах антропонима, употребляющегося в том или ином гендерном значении.

Кроме того, в EPD приводятся в виде примечания дополнительные комментарии (Note) об употреблении произносительного варианта ИС в социолектах, в речи профессиональных сообществ и т. д. Это является ценной информацией как для носителей языка, так

\section{Таблицу 1. Полное совпадение регистрации омографичных онимов и апеллятивов в LPD и EPD}

Table 1. Complete coincidence of homographic onyms and appellatives in LPD and EPD

\begin{tabular}{|c|c|}
\hline LPD & EPD \\
\hline $\begin{array}{l}\text { askew adj /a 'skju:/ } \\
\text { Askew family name /'æsk ju::/ }\end{array}$ & $\begin{array}{l}\text { askew /a 'skju:/ } \\
\text { Askew /'æs.kju:/ }\end{array}$ \\
\hline $\begin{array}{l}\text { natal /'neit }{ }^{\circ} \mathrm{l} / / \mid / \text { 'neIt }{ }^{\circ} \mathrm{l} / \\
\text { Natal province of South Africa /nə 'tæl/, /- ta:l/ }\end{array}$ & 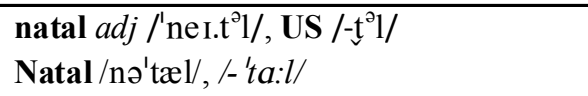 \\
\hline $\begin{array}{l}\text { scone /skpn/, /skoun/ } \| / \text { skoun/,/ska:n/ } \\
\text { Scone place in Tayside /sku:n/ }\end{array}$ & $\begin{array}{l}\text { scone /skbn/, /skaun/, US /skoun/, /ska:n/ } \\
\text { Scone/sku:n/ }\end{array}$ \\
\hline
\end{tabular}




\section{Таблица 2. Регистрация омографов Dives, Gill в LPD и EPD}

Table 2. Registration of homographs Dives, Gill in LPD and EPD

\begin{tabular}{|c|c|}
\hline LPD & EPD \\
\hline $\begin{array}{l}\text { dives from dive /daIvz/ } \\
\text { Dives name /'daIv i:z/ }\end{array}$ & $\begin{array}{l}\text { dive /darv/ -es /-z/ -ing /-ry/ -ed /-d/ } \\
\text { Dives in Bible: /'daI.vi:z/ surname: /darvz/ }\end{array}$ \\
\hline 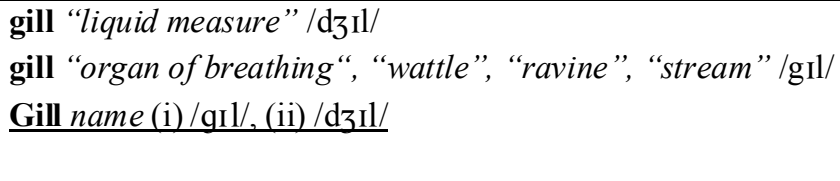 & $\begin{array}{l}\text { gill respiratory organ, ravine: /gIl/; } \\
\text { measure: / } \mathrm{d}_{3} \mathrm{l} / \\
\text { Gill family name or male first name: /gil/; } \\
\text { female first name: / } \mathrm{d}_{3} \mathrm{Il} /\end{array}$ \\
\hline
\end{tabular}

и для изучающих английский как иностранный. Например:

Benedictine monk: /,ben.I'dik.tın/, /-2'-/, /-tain/; $\underline{\mathrm{US} / \text {-tIn/,/-ti:n/ }}$

Note: Members of the order pronounce /-tin/. benedictine liqueur: /, ben.I'dık.ti:n/, /-ə'-/

Подчеркнутые нами американские произносительные варианты ИС, приведенные здесь по словарю EPD, не зафиксированы в LPD.

2. Достоинством словаря EPD является регистрация бо́льшего количества американских вариантов (реже - бо́льшего количества альтернативных британских вариантов) произношения ИС или приведение, кроме основного британского, еще и альтернативного британского варианта произношения ИС, а также указание только американского произносительного варианта ИС при его отсутствии в LPD. К таким вариантным по произношению ИС относятся: Bury 'place, surname'; Chevalier 'surname'; Faro 'place in Portugal'; Karen 'female name'; Midi 'in France'; Rouse; Said 'place'; Shona; Tonga 'Pacific islands, East Africa'; Les 'personal name'. Следует отметить, что в LPD дается более подробный комментарий о значении имени Les.

Приведем некоторые примеры регистрации произносительных вариантов ИС в LPD и EPD с нашими комментариями (см. табл. 3; в таблице нами подчеркнуты те варианты произношения, которые приведены в EPD, но отсутствуют в LPD).

3. EPD может включать три словарные статьи с дефинициями лексических единиц и конкретизацией вариантов произношения слов в зависимости от значения, в то время как в LPD омографы обычно приводятся в двух словарных статьях. Например, были обнаружены следующие омогруппы: в EPD две словарные статьи на нарицательное имя batman, то есть кроме военного термина отдельно приводится омограф, означающий меру веса (Batman). B EPD три словарные статьи, а в LPD две словарные статьи на следующие омогруппы: couch - Couch; Leghorn - leghorn; viola 'flower' - Viola 'female name'; viva 'long live' - Viva ®.

Проиллюстрируем это на примерах при сравнении данных двух словарей (см. табл. 4).

Данная особенность регистрации лексических единиц в EPD позволяет выделить омогруппы, состоящие не из двух, как в LPD, а из трех омографов.

4. В некоторых словарных статьях EPD приводятся комментарии о значениях ИС, в то время как в LPD дефиниция отсутствует (см. табл. 5 с нашими комментариями).

III. Недостатки регистрации фонетической вариантности в EPD на примере ИС, составляющих графические омогруппы с другими лексическими единицами, не являющимися ИС:

1. Некоторые омографы в EPD приводятся в одной словарной статье, что уменьшает количество омогрупп среди ИС и затрудняет поиск последних, например: Bass; bow, $B \sim$; Canton in China and Canton in Wales; cos, Cos 'island in Greece'; house, H n; Noel, Noël; Nowell; Romanes; Shona; Sue; Tonga; triton, $T \sim$.

В таблице 6 на материале двух словарей показаны особенности регистрации (с нашими комментариями) некоторых омографичных лексических единиц в одной или более словарных статьях, что влияет на количество регистрируемых в словарях омогрупп. 
Н.К. Иванова, Р.В. Кузьмина. Особенности регистрации произношения английских омографичных ИС

\section{Таблица 3. Регистрация омографов Bury, Faro, Les, Midi, Rouse, Said в LPD и EPD}

Table 3. Registration of homographs Bury, Faro, Les, Midi, Rouse, Said in LPD and EPD

\begin{tabular}{|c|c|}
\hline LPD & EPD \\
\hline $\begin{array}{l}\text { bury /'ber i/ (! =berry) } \\
\text { Bury /'ber i/ - As a family name, also /'bjuər i/ \| } \\
\text { /'bjur i/ }\end{array}$ & $\begin{array}{l}\text { bury } v / \text { 'ber.i/ } \\
\text { Bury place: /'ber.i/ surname: /'bjuə.ri/, /'ber.i/; } \\
\text { US /'bur.i/, /'ber-/ } \\
\text { В первом американском варианте произношения фа- } \\
\text { милии Bury отсутствует звук /j/ - /'bur.i/; дополни- } \\
\text { тельно приведены альтернативные британский и аме- } \\
\text { риканский варианты произношения антропонима }\end{array}$ \\
\hline $\begin{array}{l}\text { faro/'feər әv/ } \| / / \text { fer ou/,/'fær-/ (=pharaoh) } \\
\text { Faro place in Portugal /'fa:r әv/, /'feər-/ || /-ou-/ - Port } \\
\text { ['fa ru] } \\
\text { Указан исконный португальский вариант заимство- } \\
\text { ванного топонима }\end{array}$ & $\begin{array}{l}\text { faro gambling game: /'feə.rəu/; US /'fer.ou/, /'fær-/ } \\
\text { Faro in Portugal: /'fa:.rəu/,/'feə-/; US /'fa:r.ou/, /'fer-/ }\end{array}$ \\
\hline $\begin{array}{l}\text { Les personal name (i) short for Leslie /lez/, (ii) short for } \\
\text { Lester /les/ } \\
\text { les French plural "the" /lei/ - but before a vowel sound } \\
\text { /leız/ }\end{array}$ & $\begin{array}{l}\text { Les first name: /lez/; US /les/ } \\
\text { les in French phrases: /le I/, /leIz/. } \\
\text { Note: The form /leIZ/ only occurs when the following } \\
\text { word begins with a vowel. } \\
\text { К антропониму Les в LPD дан более подробный ком- } \\
\text { ментарий о сокращении ИС, а в EPD приведен амери- } \\
\text { канский вариант произношения }\end{array}$ \\
\hline $\begin{array}{l}\text { midi “mid-length (garment)"/'mId i/ } \\
\text { Midi "south of France”/mI 'di:/, /mi:-/ - Fr [mi di] } \\
\text { MIDI computer interface /'mId i// }\end{array}$ & $\begin{array}{l}\text { midi style of clothes: /'mid.i/ } \\
\text { Midi in France: /mi:'di:/,/mId'i:/; US /mi:'di/ } \\
\text { MIDI computer interface/'mid.i/ } \\
\text { Указан и американский вариант произношения топо- } \\
\text { нима }\end{array}$ \\
\hline $\begin{array}{l}\text { rouse /rauz/ } \\
\text { Rouse /raus/ }\end{array}$ & $\begin{array}{l}\text { rouse /ravz/ } \\
\text { Rouse /raus/, } / \text { ru:s/ } \\
\text { Указан альтернативный британский вариант }\end{array}$ \\
\hline $\begin{array}{l}\text { said } / \text { sed } /, \S / \text { se Id } /(!) \\
\text { Said } \text { place } / \text { said/ }\end{array}$ & 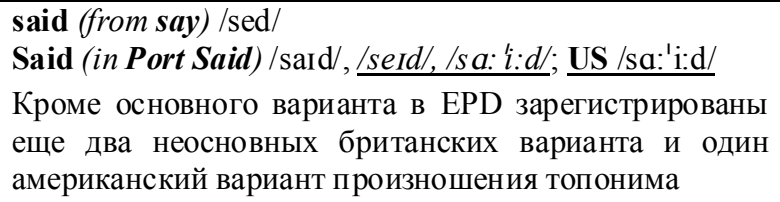 \\
\hline
\end{tabular}

\section{Таблича 4. Регистрация омографов Batman, Viva в LPD и EPD}

\section{Table 4. Registration of homographs Batman, Viva in LPD and EPD}

\begin{tabular}{|c|c|}
\hline LPD & EPD \\
\hline $\begin{array}{l}\text { batman "army servant"/'bæt mən/ } \\
\text { Batman name of cartoon character } \\
\text { /'bæt mæn/ }\end{array}$ & $\begin{array}{l}\text { batman oriental weight: /'bæt.mən/ } \\
\text { batman military: /'bæt.mən/ } \\
\text { Batman }{ }^{\circledR} / \text { 'bæt.mæn/ }\end{array}$ \\
\hline $\begin{array}{l}\text { viva “oral" /'vaIv ə/ } \\
\text { viva "long live”, Viva } t d m k \text { /'vi:v ə/ }\end{array}$ & $\begin{array}{l}\text { viva exclamation “long live” /'vi:.və/ } \\
\text { viva examination /'vaI.və/; US /'vaI.və/,/'vi:-/ } \\
\text { Viva }{ }^{\circledR} / \text { 'vi:.və/ }\end{array}$ \\
\hline
\end{tabular}


Таблица 5. Несовпадение полноты регистрации омографов Outspan, Ravel, Very в LPD и EPD

Table 5. Discrepancy of compreheniveness of homographs Outspan, Ravel, Very registration in LPD and EPD

\begin{tabular}{|c|c|}
\hline LPD & EPD \\
\hline $\begin{array}{l}\text { outspan, } \mathbf{O} \sim n / \text { 'aut spæn/ } \\
\text { outspan } v / \text {,aut 'spæn/ }\end{array}$ & $\begin{array}{l}\text { Outspan }{ }^{\circledR} / \text { 'aut.spæn/ (знак } ® \text { указывает на эрго- } \\
\text { ним - название торговой марки, а в LPD толкова- } \\
\text { ние этого ИС отсутствует) } \\
\text { outspan /aut'spæn/, /aut-/ }\end{array}$ \\
\hline $\begin{array}{l}\operatorname{ravel} / /{ }^{2}{ }^{2} \mathrm{l} / \\
\text { Ravel /ræ 'vel/, /rə-/ - Fr [ва vel] }\end{array}$ & $\begin{array}{l}\text { ravel /'ræv. }{ }^{2} \text { l/ } \\
\text { Ravel French composer: /ræv'el/; US /rə'vel/, } \\
\text { /ra:-/ (указание на имя французского композитора) }\end{array}$ \\
\hline $\begin{array}{l}\text { very /'ver i/ - Some speakers use a casual weak form /vər i/ } \\
\text { Very /'viər i/, /' ver-/ || /'ver i/, /' vIr-/ }\end{array}$ & $\begin{array}{l}\text { very adj, adv /'ver.i/ } \\
\text { Very surname: /'vıə.ri/, /'ver.i/; US /'vir.i/, } \\
\text { /'ver-/ (указание на фамилию) }\end{array}$ \\
\hline
\end{tabular}

Таблица 6. Регистрация омографов Argentine, Cave, House в LPD и EPD

Table 6. Registration of homographs Argentine, Cave, House in LPD and EPD

\begin{tabular}{|c|c|}
\hline LPD & EPD \\
\hline $\begin{array}{l}\text { Argentine "country"/'a:dz on tain/, /-ti:n/\|/'a:rdz-/ } \\
\text { Argentine "inhabitant" /'a:dz ən ti:n/, /-taIn/ \| } \\
\text { /'a:rdz-/; s /-z/ }\end{array}$ & $\begin{array}{l}\text { argentine, A /'a:.d } z^{2} \text { n.taIn/; US /'a:r.d } z^{2} \text { n.taIn/, /-ti:n/, } \\
\text { /-tIn/ } \\
\text { В EPD не представлено комментария о значениях } \\
\text { лексической единицы. Следовательно, нет возмож- } \\
\text { ности судить о корректном произношении названия } \\
\text { страны и жителя этой страны. } \\
\text { Омогруппы в словаре EPD нет }\end{array}$ \\
\hline $\begin{array}{l}\text { cave } n, v \text { "hollow"/keIv/ } \\
\text { cave } n \text { "watch" /'keIv i/ } \\
\text { cave } \text { interj /,keI 'vi:/, /'keIv i/ } \\
\text { Cave name /kerv/ }\end{array}$ & $\begin{array}{l}\text { cave, C } n, v / \mathrm{keIv/} \\
\text { cave beware: /'keI.vi/ } \\
\text { В ЕРD не зарегистрировано междометие, отдельной } \\
\text { словарной статьи с ИС нет, как нет и семантической } \\
\text { характеристики, но о существовании ИС можно дога- } \\
\text { даться по наличию в EPD варианта написания с про- } \\
\text { писной буквы в словарной статье саve, C } n, v / \text { keIv/. } \\
\text { Видно, что в ЕРD пара, а не четверка омографов }\end{array}$ \\
\hline $\begin{array}{l}\text { house } n \text {, adj /haus/; houses /'hauz Iz/, /-əz/ (!) } \\
\text { house } v \text { /hauz/ } \\
\text { House } \text { family name /haus/ }\end{array}$ & $\begin{array}{l}\text { house, H } n \text { /havs/ -ses /-zIz/ } \\
\text { house } v / \text { hauz/ } \\
\text { В одной словарной статье приведены сущ. house и } \\
\text { фамилия House, причем в EPD не уточнено значение } \\
\text { ИС. } \\
\text { Наблюдаем пару, а не тройку омографов }\end{array}$ \\
\hline
\end{tabular}

2. В EPD в отдельных словарных статьях не приводятся комментарии о значениях ИС. Напротив, в LPD различия в произношении и семантике антропонимов, топонимов, эргонимов в таких статьях установлены. Примерами ИС с теми дефинирующими указаниями, которые приводятся в LPD, являются: Ally 'personal name'; Askew 'family name'; Begin 'Israeli name'; Beth 'personal name'; Bough 'name'; Bow 'place name'; Cave 'name'; Chevy 'Chevrolet' (эргоним); Farewell 'family name'; Hades 'god of underworld';
House 'family name'; Ilium 'Troy'; Leister 'name'; $P o$ 'name'; Reading 'name'; Scone 'place in Tayside'; Slough 'place in Berks'; Trier 'place in Germany'.

Сравнительно-сопоставительный анализ отдельных омогрупп нагляднее демонстрирует данную проблему (см. примеры словарных статей в таблице 6).

3. Имеются случаи отсутствия регистрации ИС в EPD, но наличия в LPD с указанием значения слова, например: Afar 'African 
Н.К. Иванова, Р.В. Кузьмина. Особенности регистрации произношения английских омографичных ИС

people'; Alt 'name of river'; August 'personal name'; Basing 'name'; Beguine 'member of sisterhood'; Clone 'place in Ireland'; Close 'family name'; Colon, Colón 'place in Panama'; Comer 'family name'; Commune (идеоним Коммуна); Creme; Dieter; Ewe 'loch in Scotland'; Idem 'tdmk'; Kris 'personal name' (это ИС зарегистрировано в ЕРD в словосочетании Kris Kringle); Maya; Millet; Mobile; $\mathrm{Ni}, \mathrm{Ni}$ 'in Irish names'; Parsley; Poll; Ponce 'Spanish name', 'place in RP'; Psyche; Row; SEAT 'tdmk'; Taal 'volcano in Philippines'; Thais 'personal name'; Touche; Valency. Это явление проиллюстрировано на нескольких словарных примерах с нашими комментариями в таблице 7.

4. Фиксируются случаи, когда ни одно из слов омогруппы не зарегистрировано в $\mathrm{EPD}$, следовательно, количество омогрупп в EPD меньше по сравнению с LPD, например: eth-Eth; kesh-Kesh; Kos - kos; Volk-Volk (табл. 8).
5. Часто в EPD не приводится второй (неосновной) британский вариант или второй американский вариант произношения ИС либо не фиксируется узуальный, но ненормативный (non-RP) британский вариант произношения ИС, отмеченный в LPD знаком §. Примерами являются следующие лексемы: Amice; Bough; Coquet; Farewell; Halfpenny; Moray; Ould. Некоторые из них продемонстрированы в сопоставительной таблице 9.

6. Словарный анализ позволил установить, что иногда в EPD не регистрируется апеллятив в омогруппе, а ИС фиксируется. Следовательно, по EPD не выделяется омопара. Найдены следующие лексические единицы (онимы), которые, по данным словаря $\mathrm{EPD}$, не имеют графического двойника: Althea; Beth; Burry; Dene; Mousehole; Nene; Ould; Ur; Wideopen.

Можно проиллюстрировать это на примере слов Althea, Beth, Nene (см. табл. 10).

\section{Таблица 7. Несовпадение полноты регистрации омографов Alt, Poll, Taal в LPD и EPD}

Table 7. Discrepancy of compreheniveness of homographs Alt, Poll, Taal registration in LPD and EPD

\begin{tabular}{|c|c|}
\hline LPD & EPD \\
\hline $\begin{array}{l}\text { alt } \text { musical term /ælt/ } \| / \mathrm{a}: 1 \mathrm{lt} / \\
\text { Alt } \text { name of river /o:lt/, /plt/ } \| / \mathrm{p}: 1 \mathrm{tt} / \text {, a:lt / }\end{array}$ & $\begin{array}{l}\text { alt } / æ 1 t /, / o: l t / ; \text { US } / æ l t /, / a: l t / \\
\text { Указан и вариант произношения музыкального } \\
\text { термина, и вариант произношения названия ре- } \\
\text { ки, но отдельно гидроним не зарегистрирован, } \\
\text { нет указания и на дифференциацию значений } \\
\text { через произношение }\end{array}$ \\
\hline $\begin{array}{l}\text { poll } n, v / \text { pəul/, /ppul/, } \S / p p l / \| / \text { poul/ } \\
\text { Poll } \text { name /ppl/ || /pa:1/ }\end{array}$ & $\begin{array}{l}\text { poll } n, v / \text { pəul/; US } / \text { poul/ } \\
\text { ИС Poll не зафиксировано в EPD, этой пары } \\
\text { омографов не будет выявлено, если в основе } \\
\text { анализа будет только ЕРD }\end{array}$ \\
\hline $\begin{array}{l}\text { Taal "Africaans"/ta:1/ } \\
\text { Taal volcano in Philippines /ta: 'a:1/ }\end{array}$ & $\begin{array}{l}\text { Taal /ta:l/ } \\
\text { Название вулкана на Филиппинах Taal не заре- } \\
\text { гистрировано в EPD }\end{array}$ \\
\hline
\end{tabular}

\section{Таблица 8. Несовпадение регистрации омографа Volk в LPD и EPD}

\section{Table 8. Discrepancy of homograph Volk registration in LPD and EPD}

\begin{tabular}{|c|c|}
\hline LPD & EPD \\
\hline $\begin{array}{l}\text { Volk family name (i) /vplk/ || /va:lk/, (ii) } \\
\text { /vəulk/, /vpulk/ \|/voulk/ } \\
\text { Volk German, “people”/fblk/, /vplk/ \| /fb:lk/, } \\
\text { /fa:lk/- Ger [folk] } \\
\text { В LPD нет семантического комментария, по- } \\
\text { зволяющего дифференцировать фоновариан- } \\
\text { ты антропонима }\end{array}$ & $\begin{array}{l}\text { Ни одного из омографов Volk не зафиксиро- } \\
\text { вано в ЕРD. Эта омопара, как и еще три ука- } \\
\text { занные в этом пункте омопары, будет отсут- } \\
\text { ствовать в общем списке омографичных } \\
\text { групп, если проводить исследование, опира- } \\
\text { ясь только на данный лексикографический } \\
\text { источник }\end{array}$ \\
\hline
\end{tabular}


Таблица 9. Несовпадение регистрации омографов Bough, Coquet, Farewell, Moray в LPD и EPD Table 9. Discrepancy of homographs Bough, Coquet, Farewell, Moray registration in LPD and EPD

\begin{tabular}{|c|c|}
\hline LPD & EPD \\
\hline bough "branch" /bau/ (=bow "bend") & bough /bau/ \\
\hline \multirow[t]{2}{*}{ Bough name (i) /bpf/ || /bv:f/, /ba:f/, (ii) /bau/ } & Bough /bpf/; US /ba:f/ \\
\hline & $\begin{array}{l}\text { В EPD информация о вариантности произношения } \\
\text { этого имени не столь подробна }\end{array}$ \\
\hline co|quet /kd |'ket/, /kəu-/\|/kou |'ket/ & coqu|et /kpk|'et/, /kəu'k|et /; US /kou'k|et/ \\
\hline \multirow[t]{2}{*}{ Coquet /'kəuk it/, $\$$ /-ət//\|/'kouk-/ } & Coquet /'kəu.kit/; US /'kou-/ \\
\hline & $\begin{array}{l}\text { В EPD не указан узуальный, но ненормативный (non- } \\
\mathrm{RP} \text { ) вариант произношения ИС, приводимый в LPD } \\
\text { после символа § }\end{array}$ \\
\hline $\begin{array}{l}\text { farewell /,feə 'wel/ \|/,fer-/, /,fær-/ } \\
\text { Farewell family name /'feə wel/, /-wəl/ } \| / \text { 'fer-/, /'fær-/ } \\
\text { B LPD и в том, и в другом слове омопары приведен, } \\
\text { кроме основного американского варианта, еще и } \\
\text { второй американский вариант произношения }\end{array}$ & $\begin{array}{l}\text { farewell /,feə'wel/; US /,fer-/ } \\
\text { Farewell /'feə.wel/, /- } w^{2} l / ; \text { US /'fer-/ }\end{array}$ \\
\hline $\begin{array}{l}\text { moray "kind of eel" /'mbr eI/, /'mo:r-/, /m॰ 'reI/, /mp-/ } \\
\| / \text { 'mo:r eI/,/'mo:r-/; /m॰ 'reI/ }\end{array}$ & $\begin{array}{l}\text { moray eel: /'mpr. eI/, /'mo:.reI/, /mo'reI/; US /mo:'reI/, } \\
\text { /mø-/ }\end{array}$ \\
\hline Moray /'m $\Lambda \mathrm{r} \mathrm{i} /, \widehat{\Lambda} /{ }^{\prime} m p r-/ \| /{ }^{\prime} \mathrm{m} 3^{\circ}: \mathrm{i} /$ (=Murray) & Moray /'m $\Lambda \mathrm{r} . \mathrm{i} / ; \mathbf{U S} /{ }^{\prime} \mathrm{m} 3^{\mathrm{u}}:-/$ \\
\hline & $\begin{array}{l}\text { В EPD не указан некорректный, но широко распро- } \\
\text { страненный в речи вариант произношения ИС, кото- } \\
\text { рого следует избегать в речи, приводимый в LPD по- } \\
\text { сле символа } \triangle\end{array}$ \\
\hline
\end{tabular}

Таблица 10. Несовпадение регистрации омографов Althea, Beth, Nene в LPD и EPD

Table 10. Discrepancy of homographs Althea, Beth, Nene registration in LPD and EPD

\begin{tabular}{|c|c|}
\hline LPD & EPD \\
\hline $\begin{array}{l}\text { Althea } \text { personal name /'æl }{ }^{\mathrm{t}} \theta \mathrm{i} \_ \text {/ } \\
\text { althea, althaea "hollyhock" /æl ' } \theta \mathrm{i}: \_ \text {ə/; } \sim \mathbf{s} / \mathrm{z} /\end{array}$ & 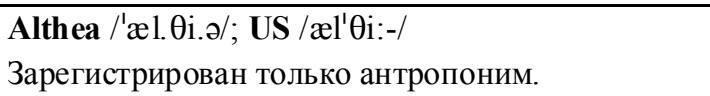 \\
\hline $\begin{array}{l}\text { beth Hebrew letter /bet/, /be } \theta / \| \text { /beit/, /beit/, /beIS/ } \\
\text { Beth personal name /be } \theta /\end{array}$ & $\begin{array}{l}\text { Beth } / \mathrm{be} \theta / \\
\text { Зафиксирован антропоним, не указано слово, } \\
\text { обозначающее название буквы в иврите }\end{array}$ \\
\hline $\begin{array}{l}\text { Nene name of river /ni:n/, /nen/ } \\
\text { nene kind of bird /'neIn eI/ }\end{array}$ & $\begin{array}{l}\text { Nene river: /ni:n/, /nen/ } \\
\text { Зарегистрирован гидроним, не отражено слово, } \\
\text { обозначающее название птицы }\end{array}$ \\
\hline
\end{tabular}

7. B EPD, в отличие от LPD, ни в одной словарной статье с ИС не указано исходное произношение заимствованного английским языком ИС (французское, немецкое, испанское, уэльское и т. д.), например: Coed 'in Welsh placenames', Fan 'Welsh mountains' (не отражены исконные национальные варианты произношения указанных топонимов, заимствованных из уэльского); Genet 'French writer'; Pascal 'proper name'; Ravel 'French composer' (не указаны исконные французские варианты произношения данных антропонимов); Trier 'place in Germany' (не отражен исконный немецкий произносительный вариант топонима) и др. Этот же недостаток выявлен в словарных статьях омографов Faro 'place in Portugal', Midi 'south of France', Ravel 'French composer', Trier 'place in Germany', которые были представлены выше в сравнительных таблицах. Заметим, что в некоторых англоязычных СМИ от дикторов требуют ориентации в произношении на оригинальный вариант звучания ИС.

8. Иногда в EPD в одной словарной статье приведены варианты произношения двух омонимичных слов, зарегистрированных в LPD в двух отдельных словарных статьях, но ИС зафиксировано в отдельной словарной статье. Следовательно, в ЕРD будет представлена пара, а не тройка омографов, например: dowse - Dowse (см. табл. 11); gill - Gill (см. табл. 2); laver - Laver. 
Н.К. Иванова, Р.В. Кузьмина. Особенности регистрации произношения английских омографичных ИС

IV. Расхождения, обнаруженные при сравнении регистрации в двух словарях вариантов произношения графически идентичных слов:

1. В отдельных словарных статьях не совпадают американские варианты произношения ИС, а основной и допустимый британские варианты приводятся в обратной последовательности. Пример такого расхождения представлен в таблице 12 (различия подчеркнуты).

2. Не совпадают американские варианты произношения омогрупп: Ate 'Greek goddess' - ate; bourbon - Bourbon 'dynasty'; bury - Bury 'place and surname'; pear - Pear 'family name' (см. табл. 13). Наличие различий в американском произношении были подтверждены при составлении LPD с данными, полученными в результате масштабного опроса носителей английского языка разных со- циальных групп и возрастов (opinion poll) (подчеркнуты нами).

3. Имеются расхождения в представлении основного британского варианта произношения ИС, а также основной и допустимый британские варианты произношения ИС приводятся в другом порядке, например: Fiat 'tdmk'; Fries 'American family name'; Ilium 'Troy'; Sue. В сопоставительной таблице 14 эти различия подчеркнуты.

4. Значительные несовпадения обнаружены в представлении различных вариантов произношения ИС. В EPD приводятся три американских варианта произношения ИС Pascal, в то время как в LPD не дано ни одного американского варианта произношения этого онима. Кроме того, в LPD, помимо основного, приводятся еще три альтернативных произносительных варианта и оригинальный французский (см. табл. 15).

\section{Таблица 11. Несовпадение регистрации омографа Dowse в LPD и EPD}

Table 11. Discrepancy of homograph Dowse registration in LPD and EPD

\begin{tabular}{|l|l|}
\hline \multicolumn{1}{|c|}{ LPD } & \multicolumn{1}{|c|}{ EPD } \\
\hline dowse “seek underground water or minerals"/dauz/ & dowse/dauz/,/daus/ \\
dowse "drench", "extinguish” /daus/ & Dowse/daus/ \\
Dowse/daus/ & Не указаны значения омографов \\
\hline
\end{tabular}

Таблииа 12. Регистрация американского и британского вариантов произношения омографа Triton в LPD и EPD

Table 12. Registration of American and British pronunciation variants of homograph Triton in LPD and EPD

\begin{tabular}{|c|c|}
\hline$\angle P D$ & $E P D$ \\
\hline $\begin{array}{l}\text { Triton "sea god", "mollusc”, "satellite of } \\
\text { Neptune", } \mathbf{t} \sim / \text { 'trait }{ }^{\circ} \mathrm{n} /, /-\mathrm{pn} / \| / \text { /-a:n/ } \\
\text { triton "nucleus of a tritium atom"//trait } \mathrm{pn} / \text {, } \\
/{ }^{\circ} \mathrm{n} / \| \text { /-a:n/ }\end{array}$ & 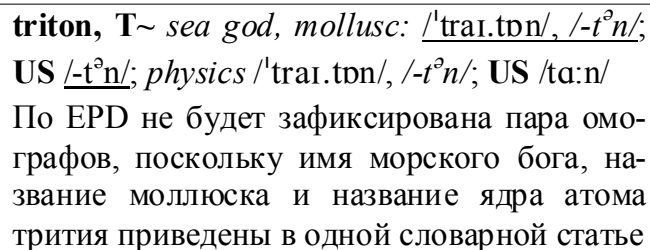 \\
\hline
\end{tabular}

Таблица 13. Регистрация американского варианта произношения омографов Ate, Pear в LPD и EPD

Table 13. Registration of American pronunciation variant of homographs Ate, Pear in LPD and EPD

\begin{tabular}{|c|c|}
\hline LPD & EPD \\
\hline $\begin{array}{l}\text { Ate Greek goddess /'a:t i/, /'eIt-/, /-i:/ } \| \text { /'eIt i/ } \\
\text { ate past of eat /et/, /e It/ } \| / \text { eIt } \bigwedge \text { /et/ } \\
\text { BrE poll panel preference: /et/ } 55 \% \text {, /eIt/ } 45 \% \text {. } \\
\text { In AmE, however, /et/ is considered non- } \\
\text { standard }\end{array}$ & $\begin{array}{l}\text { Ate } n / \text { 'a:.ti/, /'eI-/; US /'a:-/ } \\
\text { ate (from eat) /et/, /eIt/; US /eIt/ }\end{array}$ \\
\hline $\begin{array}{l}\text { pear /peə/ } \| / \mathrm{pe}^{\partial} \mathrm{r} /, / p \mathfrak{x}^{\partial} \mathrm{r} / \text { (=pair) } \\
\text { Pear family name /pıə/ } \| / \text { pe }^{\partial} \mathrm{r} /\end{array}$ & $\begin{array}{l}\text { pear } / \text { peər}^{\mathrm{r}} / \text {; US /per/ } \\
\text { Pear surname: /pıər/; US /pir/ }\end{array}$ \\
\hline
\end{tabular}


Таблиц̧а 14. Регистрация вариантов произношения омографов Fiat, Fries, Ilium в LPD и EPD

Table 14. Registration of pronunciation variants of homographs Fiat, Fries, Ilium in LPD and EPD

\begin{tabular}{|c|c|}
\hline LPD & \multirow{4}{*}{$\begin{array}{l}\text { EPD } \\
\text { fiat decree: /'faI.æt/; US /'fi:.ət/, /-æt/, /-a:t/ } \\
\text { Fiat }{ }^{\circledR} \text { /fiət/, /'fi:.æt/; US } \| / / \text { fi:.a:t/ } \\
\text { Расхождения в регистрации основного британского } \\
\text { фоноварианта эргонима }\end{array}$} \\
\hline fiat /'fi: æat/, /'faI-/, /-ət//|| /-a:t/ & \\
\hline Fiat $t d m k /$ /'fi: $\partial \mathrm{t} /, /-æ t / \| /-\mathrm{a}: \mathrm{t} /$ & \\
\hline & \\
\hline fries / fraiz/ & fries (from fry) / fraiz/ \\
\hline Fries American family name /fri:z/ & Fries /fri:s/, /fri:z/ \\
\hline & $\begin{array}{l}\text { В EPD вариант произношения антропонима /fri:z/ } \\
\text { зарегистрирован не как основной, а как допусти- } \\
\text { мый британский вариант }\end{array}$ \\
\hline ili|um /'sl i」|əm/ & ili|um /'Il.i|.əm/; -a /-ə/ \\
\hline Ilium "Troy" /'arl i om/,/'Il-/ || /'Il-/ & Ilium /'Il.i.əm/, /'ar.li-/ \\
\hline & $\begin{array}{l}\text { Основной и неосновной (допустимый) британские } \\
\text { варианты приведены в обратном порядке }\end{array}$ \\
\hline
\end{tabular}

\section{Таблица 15. Регистрация фоновариантов омографа Pascal в LPD и EPD}

Table 15. Registration of pronunciation variants of homograph Pascal in LPD and EPD

\begin{tabular}{|c|c|}
\hline LPD & EPD \\
\hline $\begin{array}{l}\text { pascal “unit of pressure”/'pæsk }{ }^{2} 1 /, /_{(,)} p \mathfrak{}{ }^{\prime} \text { skæl/ } \| \\
/_{(,)} \text {pa: ' ska:1/ }\end{array}$ & pascal /'pæs.k ${ }^{\curvearrowright} 1 /, /^{\prime} p a: . s k^{\curvearrowright} l / ; \mathbf{U S} /{ }^{\prime}$ pæs.k ${ }^{\curvearrowright} 1 /$ \\
\hline $\begin{array}{l}\text { Pascal proper name; computer language /(, pæ 'skæl/, } \\
\text { /-'ska:l/, /'pæask æl/, /-a:l/, / }{ }^{\circ} l / \text { - Fr ['pa skal] }\end{array}$ & $\begin{array}{l}\text { Pascal, PASCAL /pæs'kæl/, /-'ka:l/; } \\
\text { US /pæs'kæl/, /pa: 'skæl/, /'- - / }\end{array}$ \\
\hline
\end{tabular}

\section{Заключение}

Сопоставительный анализ принципов регистрации в орфоэпических словарях «Cambridge English Pronouncing Dictionary» Д. Джоунза и «Longman Pronunciation Dictionary» Дж. Уэллса имен собственных, входящих в группы омографов, и их фонетических вариантов показал, что, как правило, омографичные ИС представлены в EPD с теми же вариантами произношения, что и в LPD. Однако незначительные отклонения можно наблюдать в регистрации национальных вариантов (британского и американского) произношения ИС. Некоторые омогруппы, извлеченные из LPD в результате сплошной выборки, в EPD не находят полной регистрации: может быть отражено одно из двойки-тройки слов, причем незафиксированным оказывается как имя собственное, так и апеллятив. Следовательно, количество омогрупп, включающих ИС, меньше в ЕРD по сравнению с LPD. B EPD варианты произ- ношения омографов часто фиксируются в одной словарной статье, и, если не дается никаких указаний на значения лексических единиц, это затрудняет поиск корректного варианта произношения.

Преимущества словаря EPD заключаются в регистрации в словарных статьях нескольких британских и нескольких американских вариантов произношения ИС, а также в наличии дополнительных комментариев о произносительных вариантах и о семантике ИС.

Несмотря на некоторые расхождения в представлении в LPD и EPD онимов, входящих в омогруппы с апеллятивами, следует отметить, что оба словаря дают весьма полную информацию об особенностях произношения, о фоновариантах омографов и семантике английских имен собственных. Эти данные необходимы для дифференциации значений ИС и, как следствие, корректного употребления их в устной речи. Такие данные будут полезны при разработке учебных пособий, методических указаний и справочников, содержащих 
информацию об именах собственных, в которых с помощью транскрипции будет указано их современное произношение, а также помогут совершенствованию систем машинного перевода.

Необходимо учитывать тот факт, что проанализированные орфоэпические словари не являются специальными ономастическими лексикографическими источниками, чем и объясняются указанные неточности. Однако именно орфоэпические словари - это достоверный источник информации в ономастиконах о различиях в произношении разного рода английских имен собственных (антропонимов, топонимов, эргонимов, идеонимов и т. д.), в частности омографичных с именами нарицательными, то есть имеющих с ними сходное написание, но различающихся произношением. Полученные нами результаты важны и для ученых, которые обращаются к словарям LPD и EPD для исследования модификации британской и американской произносительных норм, в том числе на примере имен собственных, для уточнения фоновариантов этих лексических единиц в различных социолектах, для определения динамики произношения.

Перспективы нашего исследования составление электронного словаря омонимичных имен собственных и апеллятивов, в котором будут обобщены данные двух проанализированных словарей, устранены выявленные несоответствия и восстановлена полная семантическая и фонетическая информация для каждой омогруппы.

\section{СПИСОК ЛИТЕРАТУРЫ}

Алпатов В. В., 2013. Топонимические исследования в Великобритании (XX-XXI вв.): история, основные направления развития // Вопросы ономастики. № 1 (14). С. 112-131.

Березович Е. Л., 2001. Русская ономастика на современном этапе: критические заметки // Известия РАН. Серия литературы и языка. № 60 (6). C. $34-46$.

Горяев С., Спиридонов Д., 2016. Итоги и перспективы ономастической науки: взгляд из Оксфорда // Вопросы ономастики. Т. 13, № 2. С. 190 218. Рец. на кн.: The Oxford Handbook of Names and Naming / ed. by C. Hough, D. Izdebska. Oxford : Oxford Univ. Press, 2016. - xxiii, 771 p.
Иванова Н. К., Кузьмина Р. В., Мощева С. В., 2014. Система письма в английском языке и современный узус: язык, виртуальная коммуникация, реклама. М. : РИОР: ИНФРА-М. 238 с. DOI: https://doi.org/10.12737/1479.

Ильин Д. Ю., 2017. Изменение ономастических единиц: возможности отражения в туристическом дискурсе // Вестник Волгоградского государственного университета. Серия 2, Языкознание. Т. 16, № 4. С. 129-136. DOI: https:// doi.org/10.15688/jvolsu2.2017.4.11.

Ильин Д. Ю., 2018. Лингвоэкологический портрет регионального топонимикона: критерии описания // Вестник Волгоградского государственного университета. Серия 2, Языкознание. Т. 17, № 3. С. 99-107. DOI: https://doi.org/ 10.15688/jvolsu2.2018.3.10.

Кузьмина Р. В., 2017. Сравнительно-сопоставительный анализ регистрации омографических имен собственных в орфоэпических словарях EPD Д. Джоунза и LPD Дж. Уэллса // Известия высших учебных заведений. Серия «Гуманитарные науки». Т. 8, вып. 3. С. 240-249.

Кузьмина Р. В., 2007. Фонетическая вариативность и вариантность в английском языке и принципы их отражения в современных орфоэпических словарях (фонетико-лексикографическое исследование на материале феномена омонимии) : дис. ... канд. филол. наук. СПб. 282 с.

Кузьмина Р. В., 2009. Фонетическая вариативность омонимичных имен собственных (на материале английского языка) // Иностранный язык в техническом вузе: проблемы и перспективы преподавания : материалы Всерос. науч.-практ. конф. (г. Иваново, 4-6 июня 2009 г.). С. 27-32.

Леонович Е. О., Сизова Е. А., 2018. Географический термин в урбанонимии Великобритании и США // Иностранные языки в школе. № 8. C. $42-49$.

Леонович О. А., 1990. Англоязычные ономастические словари // Вопросы английской лексикологии и лексикографии. Пятигорск: ПГПИ. С. 38-46.

Суперанская А. В., 1985. Что такое топонимика? / под. ред. Г. В. Степанова. М. : Наука, 182 с.

Суперанская А. В., Суслова А. В., 1981. Современные русские фамилии / под. ред. Ф. П. Филина. М. : Наука. $176 \mathrm{c}$.

Callary E., 2012. Onomastics // The Year's Work in English Studies. Oxford: OUP. P. 61-70.

Owen H. W., 1981. English and Welsh Place-names in Three Lordships ofFlintshire// Nomina. Vol. 5. P. 48-53.

Parsons D. N., 2013. Martyrs and Memorials. Merthyr Place-names and the Church in Early Wales. Aberystwyth : Canolfan Uwchefrydiau Cymreig a Cheltaidd Profysgol Cymru. 111 p. 
Perono Cacciafoco F., 2013. Water Place Names in the Pre-Latin Ligurian Context. A Study in Prehistoric Toponomastics and Semantics // Вопросы ономастики. № 2 (15). С. 91-107.

Postles D., 2002. Naming, Society and Regional Identity. Oxford : Leopard's Head Press. 271 p.

The Oxford Handbook of Names and Naming, 2016 / ed. by C. Hough, D. Izdebska. Oxford : Oxford Univ. Press. xxiii, 771 p.

\section{СЛОВАРИ}

$E P D$ - Jones D. Cambridge English Pronouncing Dictionary / ed. by P. Roach, J. Setter, J. Esling. $18^{\text {th }}$ ed. Cambridge : Cambridge University Press, 2011.580 p.

$L P D$ - Wells J. C. Longman Pronunciation Dictionary. $1^{\text {st }}$ ed. Harlow : Pearson Longman, 1990. 560 p.; $2^{\text {nd }}$ ed. Harlow : Pearson Longman, 2000. 870 p.

\section{REFERENCES}

Alpatov V.V., 2013. Toponimicheskie issledovaniya v Velikobritanii (XX-XXI vv.): istoriya, osnovnye napravleniya razvitiya [Toponymic Researches in the UK (XX-XXI Centuries): History, Main Directions of Development]. Voprosy onomastiki [Problems of Onomastics], no. 1 (14), pp. 112-131.

Berezovich E.L., 2001. Russkaya onomastika na sovremennom etape: kriticheskie zametki [Russian Onomastics at the Present Stage: Critical Notes]. Izvestiya RAN. Seriya literatury i yazyka [The Bulletin of the Russian Academy of Sciences: Studies in Literature and Language], no. 60 (6), pp. 34-46.

Goryaev S.O., Spiridonov D.S., 2016. Itogi i perspektivy onomasticheskoy nauki: vzglyad iz Oksforda [Results and Prospects of Onomastic Science: A View from Oxford].Voprosy onomastiki [Problems of Onomastics], vol. 13, no. 2, pp. 190218. Book Review: Hough C., Izdebska D., eds. The Oxford Handbook of Names and Naming. Oxford, Oxford Univ. Press, 2016. xxiii, $771 \mathrm{p}$.

Ivanova N.K., Kuzmina R.V., Moshcheva S.V., 2014. Sistema pisma $v$ angliyskom yazyke $i$ sovremennyy uzus: yazyk, virtualnaya kommunikatsiya, reklama [A System of Writing in the English Language and Modern Language Usage: Language - Virtual Communication Advertisement]. Moscow, RIOR Publ., INFRA-M Publ. 238 p. DOI: 10.12737/1479.

Ilyin D.Yu., 2017. Izmenenie onomasticheskikh edinits: vozmozhnosti otrazheniya $\mathrm{v}$ turisticheskom diskurse [Change of Onomastic Units: The Possibility of Reflection in Tourism Discourse]. Vestnik Volgogradskogo gosudarstvennogo universiteta. Seriya 2. Yazykoznanie [Science Journal of Volgograd State University. Linguistics], vol. 16, no. 4, pp. 129-136. DOI: https://doi.org/10.15688/jvolsu2.2017.4.11.

Ilyin D. Yu., 2018. Lingvoekologicheskiy portret regionalnogo toponimikona: kriterii opisaniya [Linguoecological Portrait of Regionaltoponymicon: Description Attributes]. Vestnik Volgogradskogo gosudarstvennogo universiteta. Seriya 2. Yazykoznanie [Science Journal of Volgograd State University. Linguistics], vol. 17, no. 3, pp. 99-107. DOI: 10.15688/jvolsu2.2018.3.10.

Kuzmina R.V., 2017. Sravnitelno-sopostavitelnyy analiz registratsii omograficheskikh imen sobstvennykh v orfoepicheskikh slovaryakh EPDD. Dzhounza i LPD Dzh. Uellsa [Comparative Analysis of the Registration of Homographic Proper Names in the Orthoepic Dictionaries EPD D. Jones and LPD J. Wells]. Izvestiya vysshikh uchebnykh zavedeniy. Seriya "Gumanitarnye nauki» [News of Higher Schools. Series "Humanities"], vol. 8, iss. 3, pp. 240-249.

Kuzmina R.V., 2007. Foneticheskaya variativnost $i$ variantnost $v$ angliyskom yazyke $i$ printsipy $i k h$ otrazheniya $v$ sovremennykh orfoepicheskikh slovaryakh (fonetiko-leksikograficheskoe issledovanie na materiale fenomena omonimii): dis. ... kand. filol. nauk [Phonetic Variability and Variation in the English Language and the Principles of Their Reflection in Modern Orthoepic Dictionaries (Phonetic-Lexicographic Study on the Material of the Homonymy Phenomenon). Cand. philol. sci. diss.]. Saint Petersburg. 282 p.

Kuzmina R.V., 2009. Foneticheskaya variativnost omonimichnykh imen sobstvennykh (na materiale angliyskogo yazyka) [Phonetic Variability of Homonymic Proper Names (On the Material of the English Language)]. Inostrannyy yazyk $v$ tekhnicheskom vuze: problemy $i$ perspektivy prepodavaniya: materialy Vseros. nauch.-prakt. konf. (g. Ivanovo, 4-6 iyunya 2009 g.) [Foreign Language in a Technical University: Problems and Prospects of Teaching. Proceedings of the All-Russian Scientific and Practical Conference (Ivanovo, June 4-6, 2009]. Ivanovo, Ivanovskiy gosudarstvennyy khimikotekhnologicheskiy universitet, pp. 27-32.

Leonovich E.O., Sizova E.A., 2018. Geograficheskiy termin v urbanonimii Velikobritanii i SShA [Geographical Term in Urban Names of Great Britain and the USA]. Inostrannye yazyki $v$ shkole, no. 8, pp. 42-49. 
Н.К. Иванова, Р.В. Кузьмина. Особенности регистрации произношения английских омографичных ИС

Leonovich O.A., 1990. Angloyazychnye onomasticheskie slovari [English Onomastic Dictionaries]. Voprosy angliyskoy leksikologii i leksikografii [Problems of English Lexicology and Lexicography]. Pyatigorsk,PGPI, pp. 38-46.

Superanskaya A.V., 1985. Chto takoe toponimika? [What Is Toponymy?]. Moscow, Nauka Publ. $182 \mathrm{p}$.

Superanskaya A.V., Suslova A.V., 1981. Sovremennye russkie familii [Modern Russian Surnames]. Moscow, Nauka Publ. $176 \mathrm{p}$.

Callary E., 2012. Onomastics. The Year's Work in English Studies. Oxford, OUP, pp. 61-70.

Owen H.W. English and Welsh Place-Names in Three Lordships of Flintshire. Nomina, vol. 5, pp. 48-53.

Parsons D.N., 2013. Martyrs and Memorials. Merthyr Place-Names and the Church in Early Wales. Aberystwyth, Canolfan Uwchefrydiau Cymreig a Cheltaidd Profysgol Cymru. 111 p.
Perono CacciafocoF., 2013. Water Place Names in the PreLatin Ligurian Context. A Study in Prehistoric Toponomastics and Semantics. Voprosy onomastiki [Problems of Onomastics], no. 2(15), pp.91-107.

Postles D., 2002. Naming, Society and Regional Identity. Oxford, Leopard's Head Press. $271 \mathrm{p}$.

Hough C., Izdebska D., eds., 2016. The Oxford Handbook of Names and Naming. Oxford, Oxford Univ. Press. xxiii, 771 p.

\section{DICTIONARIES}

Jones D. Cambridge English Pronouncing Dictionary. Cambridge, Cambridge University Press, $2011.580 \mathrm{p}$.

Wells J. C. Longman Pronunciation Dictionary. $1^{\text {st }}$ ed. Harlow, Pearson Longman, 1990. 560 p.; $2^{\text {nd }}$ ed. Harlow, Pearson Longman, 2000. 870 p.

\section{Information About the Authors}

Natalya K. Ivanova, Doctor of Sciences (Philology), Professor, Head of the Department of Foreign Languages and Linguistics, Ivanovo State University of Chemistry and Technology, Prosp. Sheremetevskiy, 7, 153000 Ivanovo, Russia, nkiisuct@mail.ru, https://orcid.org/0000-0002-0440-6943

Rimma V. Kuzmina, Candidate of Sciences (Philology), Associate Professor, Department of Foreign Languages and Linguistics, Ivanovo State University of Chemistry and Technology, Prosp. Sheremetevskiy, 7, 153000 Ivanovo, Russia, rvkuzmina@mail.ru, https://orcid.org/0000-0001-9914-3877

\section{Информация об авторах}

Наталья Кирилловна Иванова, доктор филологических наук, профессор, заведующая кафедрой иностранных языков и лингвистики, Ивановский государственный химико-технологический университет, просп. Шереметевский, 7, 153000 г. Иваново, Россия, nkiisuct@mail.ru, https://orcid.org/0000-0002-0440-6943

Римма Владимировна Кузьмина, кандидат филологических наук, доцент кафедры иностранных языков и лингвистики, Ивановский государственный химико-технологический университет, просп. Шереметевский, 7, 153000 г. Иваново, Россия, rvkuzmina@mail.ru, https://orcid.org/0000-0001-9914-3877 